\title{
Video assisted thoracic surgery for spontaneous pneumothorax
}

\author{
Richard G Berrisford, Richard D Page \\ The Cardiothoracic Centre, Liverpool, UK
}

Introductory article

\section{Safety and efficacy of video-assisted thoracic surgical techniques for the treatment of spontaneous pneumothorax}

\section{KS Naunheim, MJ Mack, SR Hazelrigg, MK Ferguson, PF Ferson, TM Boley, RJ Landreneau}

Video-assisted thoracic surgery has been widely used in the treatment of spontaneous pneumothorax despite a paucity of data regarding the relative safety and long-term efficacy for this procedure. We reviewed 113 consecutive patients (68 male and 45 female patients, aged 15 to 92 years, mean 35.1) who underwent 121 video-assisted thoracic surgical procedures during 119 hospitalizations from 1991 through 1993. Recurrent ipsilateral pneumothorax was the most frequent indication for surgery and occurred in 77 patients (65\%). The most common method of management was stapling of an identified bleb in the lung, which was undertaken in 105 (87\%) patients. No operative deaths occurred. Complications included an air leak lasting longer than 5 days in $10(8 \%)$ patients, two of whom required second procedures for definitive management. No episodes of postoperative bleeding or empyema occurred. The postoperative stay ranged from 1 day to 39 days (median 3 days, average 4.3 days) and 99 patients (84\%) were discharged within 5 days. Mean follow-up was 13.1 months and ranged from 1 to 34 months. Eleven patients (10\%) were lost to follow-up. Ipsilateral pneumothorax recurred after five of 121 procedures $(4.1 \%)$. Twelve perioperative parameters (age, gender, race, smoking history, site of pneumothorax, severity of pneumothorax, operative indications, number of blebs, site of blebs, bleb ablation, method of pleurodesis, and prolonged postoperative air leak) were entered into univariate and multivariate analysis to identify significant independent predictors of recurrence. The only independent predictor of recurrence was the failure to identify and ablate a bleb at operation, which resulted in a $23 \%$ recurrence rate versus a $1.8 \%$ rate in those with ablated blebs $(p<0.001)$. These data suggest that video-assisted thoracic surgery is a viable alternative to thoracotomy for the treatment of recurrent spontaneous pneumothorax. It results in a short hospital stay, low morbidity, high patient acceptance, and a low rate of recurrence. (J Thorac Cardiovasc Surg 1995:109:1198-204)

Over the last decade minimally invasive surgery (small incisions and indirect visualisation of the body using an endoscope with a video link) has become established in several surgical specialties. Laparoscopic cholecystectomy is now a routine procedure, having first been performed in 1987, resulting in only a minority of patients requiring the more traditional open cholecystectomy. ${ }^{1}$ Indeed, when an attempt was made to compare the two techniques scientifically, the advantages of the laparoscopic approach led to difficulties in completing the trial. ${ }^{2}$

Video assisted thoracoscopic surgery (VATS) evolved soon afterwards. Like laparoscopy in the abdomen, rigid thoracoscopy was first described many years ago ${ }^{3}$ but, until recently, its use was limited to viewing and taking biopsy specimens of pleura and mediastinum. ${ }^{4}$ However, with the improvement in imaging and instrumentation, virtually every standard thoracic surgical procedure has been described using video assisted techniques. ${ }^{5}$ This has included procedures such as major lung ${ }^{6}$ and oesophageal ${ }^{7}$ resections.

Although some institutions are still attempting to pursue video assisted techniques for all surgical procedures, most units have found VATS to be clinically useful only in a relatively limited number of applications compared with the scope of thoracic surgery as a whole. ${ }^{8}$ The three main groups of patients being treated with VATS techniques are those requiring lung biopsy for diffuse parenchymal disease, wedge excision of an unidentified intrapulmonary mass, and in the management of pneumothorax. Many other less common procedures are frequently carried out, making up a large heterogeneous fourth group (box).

Philosophy of minimally invasive surgery The principal difference between VATS procedures and traditional "open" operations is the size of the incision 


\section{VATS operations}

Established procedures

Management of pneumothorax

Lung biopsy for diffuse parenchymal disease

Wedge biopsy of unidentified pulmonary nodule

Cervical sympathectomy

Pericardial window

Biopsy specimens of mediastinal lesions

Pleural biopsy

Management of early empyema

Evolving/under investigation

Major pulmonary resection

primary carcinoma

metastatectomy

Lung cancer staging

Thoracic trauma

Lung volume reduction surgery

Excision of mediastinal/chest wall tumours

Oesophageal resection

Oesophageal myotomy for achalasia

Repair of oesophageal perforation

Closure of patent ductus arteriosus

Coronary artery bypass surgery

Heart valve replacement (animal studies only)

used for surgical access. During traditional open thoracotomy the skin and chest wall muscles are cut over a distance of $20-30 \mathrm{~cm}$ and intercostal muscles are divided throughout the length of the adjacent ribs. A sufficiently large opening is thus made in the chest wall to allow direct visualisation and instrumentation of the thoracic organs.

In contrast, a $2 \mathrm{~cm}$ incision suffices for viewing the thoracic cavity indirectly with a thoracoscope and video link. Instrumentation within the chest is accomplished through further small incisions. Surgical instrumentation and imaging systems have been specifically designed for use through small incisions. The only problems with this approach are that there is much less tactile feedback to the surgeon due to an inability to handle the tissues directly and, although the quality of the video image may be superior to that obtainable in some parts of the thorax with an open technique, the angle of view is fixed. In other words one cannot "look around" structures as in open surgery, although angled and flexible tipped endoscopes have to some extent helped in this regard.

The potential advantage of avoiding a large incision is a reduction in the "trauma of access without compromising the operative field". 9 In relation to thoracic surgery, more specific potential advantages include reduced postoperative pain, reduced postoperative pulmonary dysfunction, reduced catabolic response to the trauma of surgery, absence of wound related complications (infection and dehiscence), and earlier mobilisation, discharge from hospital, and return to preoperative status.

Despite these potential advantages, there are concerns about procedures routinely performed by VATS compared with open thoracotomy. It is a surgical tenet that adequate access is paramount for a safe successful operation. Inadequate access can compromise the results and safety of any procedure. A surgical incision is a means to an end, not an end in itself. The operative procedure within the patient is the important intervention. Many concerns have been expressed in relation to VATS for treatment of lung cancer, particularly that the full extent of a tumour may not be appreciated leading to inadequate staging and precluding complete resection. ${ }^{1011}$

After a period of evolution in any new treatment, sufficient experience is generated to be able to take stock. Currently this time has arrived for VATS, ${ }^{1213}$ having become part of the armementarium of virtually all thoracic surgeons. The introductory article by Naunheim et $a l^{14}$ has a sufficiently large patient group to comment usefully on the two most important aspects surrounding a new treatment - safety and efficacy - on this occasion in relation to the surgical treatment of spontaneous pneumothorax.

\section{Surgical management of spontaneous pneumothorax}

SURGICAL PATHOLOGY

Patients with primary and secondary pneumothorax must be considered as different populations. ${ }^{1516}$ The specific abnormality of the lung leading to a pneumothorax is a major factor that governs the surgical technique which can be used to deal with it. The pathological lesion leading to primary spontaneous pneumothorax, typically in young and otherwise fit patients, is a pulmonary bleb, usually situated at the apex of a lobe. These blebs are by definition small (less than $1 \mathrm{~cm}$ ). Although the blebs may be multiple, the intervening lung is healthy. This group of patients is easily treated surgically by many different techniques, all of which involve excision or ablation of the bleb. Virtually all cases can be treated very effectively with VATS.

In contrast, secondary pneumothorax which typically occurs in patients with emphysematous lungs is more difficult to treat surgically. The patients are usually elderly with limited pulmonary reserve and may have other medical problems. The site of the air leak may be a bulla or a generally emphysematous part of the lung. The bullae are often of complex shape, being multilocular, sessile, and merging into the adjacent diseased parenchyma. Rarely is a discrete, large, pedunculated bulla responsible for a pneumothorax, although if it is, this may be dealt with by ligating the neck of the bulla. Only in this latter instance is VATS easily and reliably applicable. The surgical management of all other patients in this group must be individualised. Although VATS techniques may be useful, in many instances it may be more expeditious and therefore safer to carry out a formal thoracotomy to ensure the condition is dealt with effectively.

Current advances in lung volume reduction surgery which can be carried out using VATS ${ }^{1718}$ add further to the options in surgical management of secondary pneumothorax. If lung volume reduction can be achieved at the same time as closing an air leak, a more aggressive surgical approach to pneumothorax in these patients may be justified. Pneumothorax secondary to infection with Pneumocystis in patients with AIDS is increasingly becoming a surgical problem. ${ }^{1920}$

INDICATIONS FOR SURGICAL TREATMENT

Surgical intervention is indicated in patients with a persistent air leak, after recurrent pneumothoraces, in cases of bilateral pneumothorax, and after a single episode of pneumothorax when a recurrence is thought to be unacceptable (for example, airline pilots or where medical attention is inaccessible). ${ }^{21}$ Soon after the introduction of VATS surgery for pneumothorax, enthusiasm for the technique was such that surgical intervention was carried out in some centres during the 
hospital admission for a first time pneumothorax, even when the air leak had spontaneously sealed and the pneumothorax had been successfully aspirated. This unnecessary trend now appears to have become less common.

The advent of VATS techniques ought not to have changed the standard indications for surgical treatment of pneumothorax, as the pathology responsible for the condition is the same. However, it is interesting that, given the popular image within the medical profession that VATS is safer than a formal thoracotomy, we have found that patients are being referred to surgical centres earlier than previously with a persistent air leak and after fewer recurrences.

Spontaneous closure of air leaks has been shown to be maximal at 48 hours of intercostal drainage, ${ }^{22}$ so there is little benefit from conservative management of primary pneumothorax with an air leak for longer than 72 hours. ${ }^{23}$ However, surgical intervention for a prolonged air leak has been getting progressively earlier. ${ }^{21}$ Patients with secondary pneumothorax are at higher risk from surgery and so non-operative techniques of management may be tried for longer periods. Nevertheless, in selected patients in whom formal thoracotomy is thought to be unsafe, VATS techniques may be useful, leading to a surgical option and possibly better results overall from treatment.

\section{IS THORACOSCOPY USEFUL IN IDENTIFYING WHICH} PATIENTS NEED SURGICAL INTERVENTION?

There is no significant difference in the thoracoscopic appearance between cases of first and recurrent pneumothorax..$^{24}$ Linder et $a l^{25}$ performed a thoracoscopy on 78 patients with first time pneumothorax and found bullae or adhesions in only $17(22 \%)$. Thoracoscopy during admission for a first pneumothorax is therefore not a valid treatment strategy. Only about $20 \%$ of patients who present with primary spontaneous pneumothorax will have further episodes, so blanket surgical treatment is not justified. ${ }^{26}$

\section{VATS VERSUS THORACOTOMY}

The question as to whether a VATS approach is superior to a thoracotomy is confused by the multiplicity of different access incisions used. Thus, the spectrum extends from the truly minimally invasive approach comprising two or three $1 \mathrm{~cm}$ incisions to a 12 inch posterolateral thoracotomy. In addition, there are $5 \mathrm{~cm}$ "utility" incisions (which is often included in VATS descriptions), axillary muscle sparing thoracotomies with a small rib spreader, limited thoracotomies with only minimal rib spreading with the standard spreader, and all points in between these approaches. Scientifically valid comparisons between techniques are therefore difficult to achieve.

There are very few scientific trials in which VATS has been compared with more conventional surgical approaches. A comparison between VATS and limited posterolateral thoracotomy (without epidural analgesia) for pneumothorax ${ }^{15}$ showed marginally better lung function in the VATS group on the third postoperative day (mean percentage decrease in forced vital capacity compared with preoperative value was $19 \%$ in VATS group and $39 \%$ in thoracotomy group, $p<0.01$ ). Mean operating times were longer in the VATS group (43 minutes versus 37.5 minutes) although, along with most other units, the authors recognise that VATS operating times are reduced as experience increases. Analgesic requirements were less in the VATS group although this difference did not reach statistical significance. The postoperative stay in hospital was similar in both groups.

No randomised trials comparing VATS with axillary thoracotomy for the treatment of pneumothorax have been published. However, Hazelrigg et al ${ }^{27}$ compared a group of 26 patients who underwent a VATS operation with a retrospective group of 20 patients subjected to axillary thoracotomy. The mean (SD) hospital stay was shorter in the VATS group $(2.88(0.99)$ versus 4.47 (1.07) days), with a decreased requirement for parenteral narcotics after 48 hours ( $2 / 26$ versus $14 / 20)$. Murray quotes an average postoperative stay of four days using an axillary approach. ${ }^{28}$ A small "utility incision" (avoiding a rib spreader) allows use of standard stapling instruments; combined with VATS for improved visualisation, the substantial cost of VATS disposable instruments may be avoided with minimal if any increase in pain. ${ }^{15}$

\section{SURGICAL TECHNIQUES}

The two components of surgical treatment of persisting or recurrent pneumothorax are (1) to identify the part of the lung responsible for the air leak and to deal with it appropriately; and (2) to prevent collapse of the lung in the future by promoting adhesions between the lung and chest wall.

\section{Ablation of the site of an air leak}

Stapling devices (figure) are probably the treatment of choice in young patients with primary spontaneous pneumothorax and apical blebs. ${ }^{27}$ About $85 \%$ of patients with recurrent primary spontaneous pneumothorax will have pulmonary blebs in the apex of the upper lobe. ${ }^{29}$ With this figure in mind, if a bleb cannot be visualised in any part of the lung it is reasonable to carry out a "blind" excision of the apex of the upper lobe as discussed by Naunheim et al. ${ }^{14}$

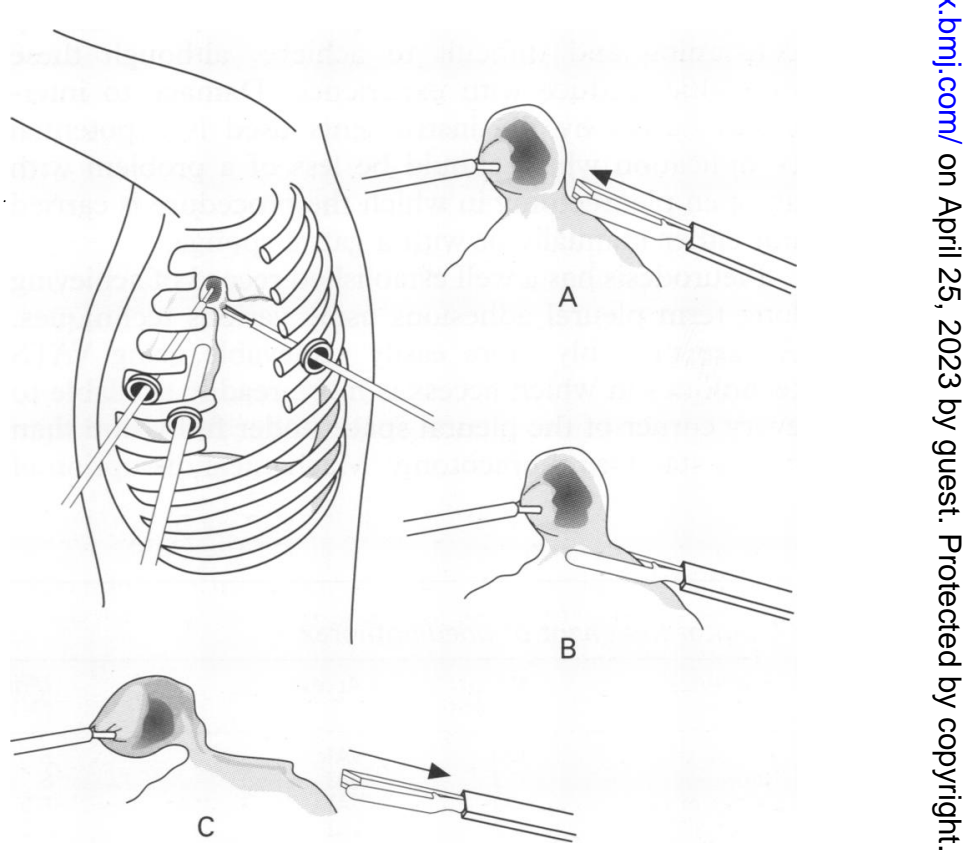

Approximate sites of routine trocar placement for spontaneous pneumothorax and demonstration of stapled resection of an apical bleb. The bleb is initially grasped (A), the endoscopic stapler is applied with a rim of normal lung tissue (B), and each staple application cuts between six rows of staples (C). Reproduced from Hazelrigg et $a /^{27}$ with permission. 
Staplers can result in prolonged air leaks in patients with larger or broad-based bullae where multiple applications of an endoloop may be better. ${ }^{30}$ The disadvantage of endoloops is their potential for falling off on lung re-expansion. ${ }^{3132}$ Bovine pericardial strips are now available commercially for buttressing staple lines in diseased lung, reducing air leaks. ${ }^{33}$ Very large, complex and sessile bullae may preclude a video assisted thoracoscopic approach ${ }^{3435}$ because of the difficulties in accurate visualisation and manipulation.

The development of endoscopic staplers which can be inserted through a $1-2 \mathrm{~cm}$ incision has been a real boost to VATS techniques, especially the more recently introduced instruments which have longer and more widely diverging jaws. The endoscopic instruments are generally more costly and delicate than their more robust stapling counterparts designed for open surgery. The latter can be inserted through a utility incision, which may allow a very good compromise between the open and VATS techniques in certain circumstances.

Besides staplers and endoloops, laser coagulation of blebs and bullae has also been advocated. ${ }^{32}$ However, it is recognised by the authors of these techniques that perforation of the bulla may occur. Our belief is that, in the setting of pneumothorax treatment, laser coagulation is not an appropriate way of dealing with blebs and bullae because of the possibility of an unacceptably high recurrence rate as reported in some recent series. ${ }^{29}$ As yet, no long term results are available to judge the efficacy of laser treatment in the management of pulmonary blebs or bullae for recurrent pneumothorax.

\section{Establishing pleural adhesions}

No technique for dealing with the parietal pleura has been found to be ideal. A full ${ }^{36}$ or apical ${ }^{15}$ pleurectomy is probably the most reliable way of achieving pleural symphysis, although in younger patients future thoracotomy for any reason could thus be made very difficult. Bleeding is not uncommon after pleurectomy and is one of the most frequent criticisms of the procedure. Using VATS techniques a full pleurectomy can be time consuming and difficult to achieve, although these difficulties reduce with experience. Damage to intercostal nerves by the instruments used is a potential complication which should be less of a problem with an open pleurectomy in which the procedure is carried out either manually or with a gauze sponge.

Pleurodesis has a well established record of achieving long term pleural adhesions using various techniques. All are probably more easily achievable using VATS techniques in which access is more readily available to every corner of the pleural space under full vision than with a standard thoracotomy. Mechanical disruption of the pleura using some sort of abrasive material is often used. ${ }^{29} 37$ Various instruments including a specially designed rotating brush have been described, ${ }^{38}$ as has laser coagulation of the pleura. Chemical pleurodesis with tetracycline or talc $\mathrm{c}^{30}$ is occasionally described, although we feel that talc should be used with caution because of the excessive granulomatous reaction it incites, as well as fears over asbestos contamination.

Our current approach is to perform an abrasive pleurodesis unless no bleb or bulla is visualised, in which case a full pleurectomy is carried out in an attempt to reduce the recurrence rate, which is known to be higher when a potential air leak cannot be controlled. ${ }^{14}$

\section{CONVERSION TO OPEN THORACOTOMY}

If it is impossible to carry out a safe and effective operation using VATS techniques, the surgeon should have no hesitation in proceeding to formal thoracotomy. This particularly applies in cases with a complex bulla in pneumothorax surgery. This should be seen as a good piece of judgement rather than a failure of a particular technique. Because of this occasional eventuality, all patients should be prepared for thoracotomy should the need for it arise, and appropriate instrumentation be made available.

Conversion rates between institutions should not be subjected to comparison, as so much depends on patient selection as well as the personality and experience of the surgeons involved. ${ }^{10}$ However, as experience accumulates conversion rates generally fall, and selection of patients to each approach - whether VATS or open - becomes more effective. The usual reasons for conversion remain unexpectedly dense pleural adhesions, an inability to collapse the lung, or a technical problem with the imaging equipment. Surgical complications such as bleeding should be exceptional.

\section{Results of surgery}

The outcome of a number of published series is shown in the table.

\section{PROBLEMS IN HOSPITAL}

In most instances mortality and major complications after surgery for pneumothorax reflect the necessity for operating on higher risk patients rather than a failure of technique. Only in the series reported by Waller et $a l^{15}$ are any deaths reported, one out of 30 in the VATS group and two out of 30 in the thoracotomy group. All were elderly patients who were being treated for secondary pneumothorax. They had already been in hospital for at least two weeks before surgery, pre-

Surgical treatment of pneumothorax

\begin{tabular}{|c|c|c|c|c|c|c|}
\hline Reference & $\begin{array}{l}\text { No. of } \\
\text { patients }\end{array}$ & Access & $\begin{array}{l}\text { Morbidity } \\
\text { (\%) }\end{array}$ & $\begin{array}{l}\text { Death } \\
(\%)\end{array}$ & $\begin{array}{l}\text { Recurrent } \\
\text { pneumothorax (\%) }\end{array}$ & $\begin{array}{l}\text { Mean (range) follow } \\
\text { up (months) }\end{array}$ \\
\hline $\begin{array}{l}\text { Yim et } a l^{29} \\
\text { Naunheim et al } \\
\text { Linder et } a l^{14} \\
\text { Liu et } a l^{30} \\
\text { Waller et } a l^{15} \\
\text { Cole et } a l^{21} \\
\text { Hazelrigg et } a l^{27}\end{array}$ & $\begin{array}{r}100 \\
113 \\
94 \\
82 \\
30 \\
30 \\
30 \\
43 \\
26 \\
20\end{array}$ & $\begin{array}{l}\text { VAT } \\
\text { VAT } \\
\text { VAT } \\
\text { VAT } \\
\text { VAT } \\
\text { Thoracotomy } \\
\text { VAT } \\
\text { Thoracotomy } \\
\text { VAT } \\
\text { Axillary thoracotomy }\end{array}$ & $\begin{array}{l}8 \\
8 \\
8 \cdot 5 \\
7 \cdot 3 \\
\text { NS } \\
\text { NS } \\
7 \\
\text { NS } \\
0 \\
0\end{array}$ & $\begin{array}{l}\text { NS } \\
\text { NS } \\
\text { NS } \\
0 \\
6 \cdot 7 \\
13 \cdot 3 \\
\text { NS } \\
\text { NS } \\
0 \\
0\end{array}$ & $\begin{array}{l}3 \\
4 \cdot 1 \\
1 \cdot 1 \\
0 \\
6 \cdot 7 \\
3 \cdot 3 \\
17 \\
3 \\
0 \\
\text { NS }\end{array}$ & $\begin{array}{l}17(8-24) \\
13 \cdot 1(1-34) \\
\text { NS } \\
22 \\
\text { NS } \\
\text { NS } \\
\text { NS } \\
\text { NS } \\
8 \\
\text { NS }\end{array}$ \\
\hline
\end{tabular}


sumably illustrating the reluctance of the surgical team to intervene because of poor general condition.

The frequency of persistent postoperative air leaks the principal postoperative complication after pneumothorax surgery - appears to be similar following both VATS and open techniques. Rapid re-inflation of the lung may cause a tear in a staple line leading to an air leak. Grasping of the lung with the endoscopic instruments causing a breach in the visceral pleura has also been blamed for this in patients undergoing VATS. ${ }^{20}$ An air leak is the main reason for a delay in discharge from hospital in patients who undergo VATS and leads to an equalisation of the postoperative stay in hospital of patients following VATS and thoracotomy. Reoperation for a large air leak may be necessary during convalescence. Nevertheless, when no air leak occurs from the drains they may be removed on the first day after surgery, allowing a large group of patients to be discharged on the first or second postoperative day. Naunheim et $a l^{14}$ reported that $84 \%$ of their patients were discharged within five days after VATS surgery with a mean stay of $4.3(4.5)$ days. This is similar to the median discharge time of four days after an axillary thoracotomy reported by Murray et al. ${ }^{28}$

\section{LATE RESULTS AND PREDICTORS OF RECURRENCE}

Standard surgical approaches to pneumothorax have resulted in long term recurrence rates of less than $5 \% .^{23289-41}$ It is to these results that any refinement in techniques such as VATS should aspire. As experience with VATS accumulates, more data will become available on long term efficacy, although currently there is little information available. Moreover, the patients who have been followed up for the longest time represent those treated by surgeons at the start of their learning curve, and as such could be expected to exhibit poorer results than the expected standard.

Both Naunheim et $\mathrm{al}^{14}$ and Yim and $\mathrm{Ho}^{29}$ cite failure to control or identify a pulmonary bleb as a predictor of recurrence. No bleb is present in some patients and in these cases the air leak is presumably from a part of the lung which is macroscopically normal. If, in a particular patient, the VATS image is poor and the lung cannot be visualised with confidence, open thoracotomy should be carried out to ensure that no bleb or bulla is missed.

On the assumption that most blebs are at the apex of the upper lobe, Naunheim et all ${ }^{14}$ suggest that blind stapling excision of the apex of the upper lobe is a reasonable option if no bleb is visible. Yim and Ho reported three recurrences in 100 patients followed up for a mean of 17 months. In one of these patients, who had a recurrence at two months, a $0.5 \mathrm{~cm}$ bleb was visualised at the original operation but was not dealt with. After the recurrence it was subsequently stapled to good effect. In another patient an apical bleb had been coagulated with an argon beam laser. A pneumothorax recurred five weeks after surgery, at which time a repeat thoracoscopy showed the bleb to be ruptured with no sign of coagulation. The bleb was then staple-resected with no further problems.

In Naunheim's series of 113 patients there were five recurrences over a mean follow up period of 13.1 months. Two patients were only observed, in two more a repeat thoracoscopic pleurodesis was carried out, and only in the fifth was a formal thoracotomy with pleurectomy thought to be necessary. Liu et al reported 82 patients followed up for a mean of 22 months after surgery without any recurrence. ${ }^{30}$

\section{Cost issues}

The trend to earlier discharge of patients after all types of surgery has evolved over the last five years, which is also the time during which VATS has been introduced. In this climate of the need to reduce health care costs, one of the advantages which VATS was expected to show over open thoracotomy was a cost saving due to earlier discharge from hospital. Unfortunately, any saving which can be achieved in this regard is offset by increased theatre costs. A modern three chip video camera system costs in the order of $£ 17000$. Additional funds are required for a light source, television monitors, laparoscopes, and reusable endoinstruments. The cost of disposable instruments such as endoscopic staplers may run into several hundred pounds per case. On the positive side, the problems of increased operating times for VATS have largely been overcome, and a more rapid turnover of cases can usually be achieved than for patients having open surgery. Overall, the financial cost of VATS remains comparable to open surgery. ${ }^{14}$

\section{Conclusions}

There is little doubt that video assisted thoracic surgery is here to stay. In some patient groups its perceived advantages over traditional open surgery are now firmly embedded in the ethos of surgical communities and, as importantly, in the attitudes of patients to surgery.

In relation to the surgical treatment of spontaneous pneumothorax, VATS techniques have been shown to be safe and effective for young fit patients with problems attributable to a small pulmonary bleb. Excision of the

\section{LEARNING POINTS}

* Inability to visualise site of air leak leads to increased recurrence.

* Type of pleural procedure is of secondary importance compared with controlling the air leak.

* Operative procedure should not be compromised by inadequate access.

* Open thoracotomy may be necessary in an individual patient regardless of the procedure carried out.

* Current data suggest that VATS may be the preferred technique for surgical treatment of primary pneumothorax. 
bleb when combined with a pleurodesis or pleurectomy has been shown to produce short and long term results comparable to those achieved with a similar procedure carried out via an open thoracotomy. Scientific data comparing one technique with the other are limited, but in terms of postoperative pain, pulmonary dysfunction, and discharge from hospital, treatment by VATS performs favourably.

Elderly patients with emphysematous lungs and complex bullous disease are a more heterogeneous group who are difficult to treat surgically by any approach. As yet it is unclear whether the results of VATS techniques can equal those of open surgery in this patient population.

VATS techniques for spontaneous pneumothorax, although useful, are not applicable to all patients. In certain circumstances, especially when access is poor or when unexpected problems arise, conversion to open thoracotomy may be necessary. As such, VATS techniques should only be carried out by personnel suitably trained in all aspects of thoracic surgery. ${ }^{42}$ As with any new technique, careful ongoing evaluation is mandatory.

1 The Southern Surgeon's Club. A prospective analysis of 1518 laparoscopic cholecystectomies. N Engl fै Med 1991;324:1073-8.

2 Neubauer E, Troidl H, Spangenberger W, Dietrich A, Lefring R. Conventional versus laparoscopic cholecystectomy and the randomised controlled trial. Br $\mathcal{F}$ Surg 1991;78:150-4.

3 Jacobeus HC. The practical importance of thoracoscopy in surgery of the chest. Surg Gynecol Obstet 1921;32:493.

4 Page RD, Jeffrey RR, Donnelly RJ. Thoracoscopy: a review of 121 consecutive procedures. Ann Thorac Surg 1989;48:66-8.

5 Hazelrigg SR, Nunchuck SK, LoCicero J. Video assisted thoracic surgery study group data. Ann Thorac Surg 1993;56:1039-43.

6 McKneally MF. Lobectomy without a rib spreader. Ann Thorac Surg 1992;54:2.

7 Gossot D, Fourquier P, Celerier M. Thoracoscopic esophagectomy: technique and initial results. Ann Thorac Surg 1993;56:667-70.

8 VATS Working Group, Society of Cardiothoracic Surgeons of Great Britain and Ireland. VATS: Guidelines for practice, training and procedure development, 1995

9 Nathanson LK, Shimi SM, Cuschieri A. Laparoscopic cholecystectomy: the Dundee technique. Br $\mathcal{F}$ Surg 1991;78:155-9.

10 Allen MS, Pairoleroa PC. Inadequacy, mortality and thoracoscopy. Ann Thorac Surg 1995;59:6.

11 Fry WA, Siddiqui A, Pensler JM, Mostafavi H. Thoracoscopic implantation of cancer with a fatal outcome. Ann Thorac Surg 1995;59: planta.

12 Moghissi K. Video-assisted thoracoscopic surgery of the lung (VATS) comes of age - where to next? Eur $\mathcal{F}$ Cardiothorac Surg 1996;10: 159-60.

13 Walker WS, Craig SR. Video-assisted thoracoscopic surgery - current status and potential evolution. Eur f Cardiothorac Surg 1996;10:161-7.

14 Naunheim KS, Mack MJ, Hazelrigg SR, Ferguson MK, Ferson PF, Boley TM. Safety and efficacy of video-assisted thoracic surgical techniques for the treatment of spontaneous pneumothorax. $₹$ Thorac Cardiovasc Surg 1995;109:1198-203.

15 Waller DA, Forty J, Morritt GN. Video-assisted thoracoscopic surgery versus thoracotomy for spontaneous pneumothorax. Ann Thorac Surg 1994;58:372-6.

16 Graham AN, McManus KG, McGuigan JA. Videothoracoscopy and spontaneolis pneumothorax. Ann Thorac Surg 1995;59:266-7.
17 Keenan RJ, Landreneau RJ, Sciurba FC, Ferson PF, Holbert JM, Brown ML. et al. Unilateral thoracoscopic surgical approach for diffuse emphysema. ₹ Thorac Cardiovasc Surg 1996;111:308-15.

18 Wakabayashi A. Thoracoscopic partial lung resection in patients with severe chronic obstructive pulmonary disease. Arch Surg 1994;129. 940-4.

19 Riquet M, Le Pimpec-Barthes F, Debrosse D, Houel R, Hubsch JP, Saab M, et al. [The surgical management of pneumothorax in patients with AIDS]. Rev Mal Respir 1995;12:151-60.

20 Slabbynck H, Kovitz KL, Vialette JP, Kasseyet S, Astoul P, Boutin C. Thoracoscopic findings in spontaneous pneumothorax in AIDS. Chest 1994;106:1582-6.

21 Cole FH Jr, Cole FH, Khandekar A, Maxwell JM, Pare JW, Walker WA. Video-assisted thoracic surgery: primary therapy for spontaneous pneumothorax? Ann Thorac Surg 1995;60:931-5.

22 Schoenenberger RA, Haefeli WE, Weiss P, Ritz RF. Timing of invasive procedures in therapy for primary and secondary spontaneous procedures in therapy for primary and

23 Granke K, Fischer CR, Gogo O, Morris JD, Prager RL. The efficacy and timing of operative intervention for spontaneous pneumothorax. Ann Thorac Surg 1986;42:540-2

24 Janssen JP, Schramel FM, Sutedja TG, Cuesta MA, Postmus PE. Videothoracoscopic appearance of first and recurrent pneumothorax. Chest 1995;108:330-4.

25 Linder A, Friedel G, Toomes $H$. Operative thoracoscopy for recurring pneumothorax. Endosc Surg Allied Technol 1993;1:253-60.

26 Weeden G, Smith GH. Surgical experience in the management of spontaneous pneumothorax, 1972-82. Thorax 1983;38:737-43.

27 Hazelrigg SR, Landreneau RJ, Mack M, Acuff T, Seifert PE, Auer JE, et al. Thoracoscopic stapled resection for spontaneous pneumothorax. f Thorac Cardiovasc Surg 1993;105:389-93.

28 Murray KD, Mathey RG, Howanitz EP, Myerowitz PD. A limited axillary thoracotomy as primary treatment for recurrent spontaneous pneumothorax. Chest 1993;103:137-42.

29 Yim AP, Ho JK. One hundred consecutive cases of video-assisted thoracoscopic surgery for primary spontaneous pneumothorax. Surg Endosc 1995;9:332-6.

30 Liu HP, Lin PJ, Hsieh MJ, Chang JP, Chang CH. Thoracoscopic surgery as a routine procedure for spontaneous pneumothorax. Results from 82 patients. Chest 1995;107:559-62.

31 Nathanson LK, Shimi SM, Wood RAB, Cushieri A. Videothoracoscopic ligation of bulla and pleurectomy for spontaneous pneumothorax. Ann Thorac Surg 1991;62:316-9.

32 Wakabayashi A. Thoracoscopic ablation of blebs in the treatment of recurrent or persistent spontaneous pneumothorax. Ann Thorac Surg 1989;48:651-3.

33 Cooper JD. Technique to reduce air leaks after resection of emphysematous lung. Ann Thorac Surg 1994;57:1038-9.

34 Mack MJ, Hazelrigg SR, Landreneau RJ, Naunheim KS. The first international symposium on thoracoscopic surgery. Ann Thorac Surg 1993:56:686-93.

35 Coosemans W, Lerut TE. Thoracoscopic surgery: the Belgian experience. Ann Thorac Surg 1993;56:721-30.

36 Page RD, Donnelly RJ, Berrisford RG. Videothoracoscopic surgery. Eur f Cardiothorac Surg 1993;7:281-6.

37 Yim AP, Ho JK, Chung SS, Ng DC. Video-assisted thoracoscopic surgery for primary spontaneous pneumothorax. Aust NZ ₹ Surg 1994, 64:667-70.

38 Smolle-Juettner FM, Pinter H, Jeran H, Popper H, Ratzenhofer B, Friehs G. Rotating brush for video-assisted thoracoscopic pleural abrasion. Eur f Cardiothorac Surg 1994;8:657-9.

39 Thomas P, Le Mee F, Le Hors H. Surgical management of persistent or recurrent pneumothorax. Ann Chir: Chir Thorac Cardiovasc 1993; 47:136-40.

40 Youmans CR, Williams RD, McMinn MR, Derrick LR. Surgical management of spontaneous pneumothorax by bleb ligation and pleural dry sponge abrasion. Am $\mathcal{F}$ Surg 1970;120:644-8.

41 Brooks JW. Open thoracotomy in the management of spontaneous pneumothorax. Ann Surg 1973;177:798-805.

42 McKneally MF, Lewis RJ, Anderson RP, Fosburg RG, Gay WA, Jones $\mathrm{RH}$, et al. Statement of the AATS/ST Joint Committee on Thoracoscopy and Video-assisted Thoracic Surgery. Ann Thorac Surg 1992, 54:1. 